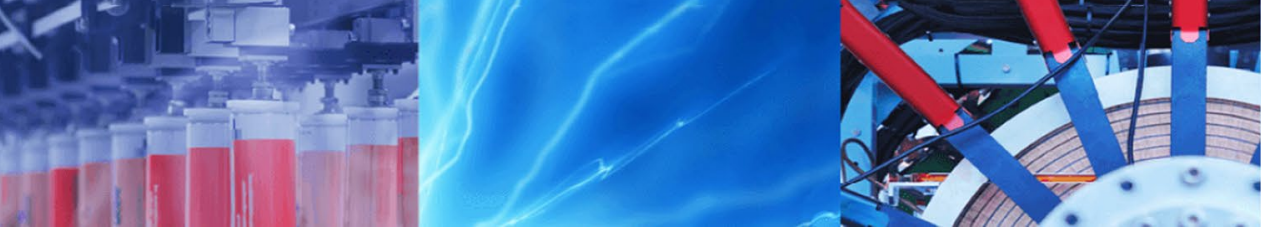

Research Article

\title{
Improved disturbance rejection with modified Smith predictor for integrating FOPTD processes
}

\author{
Somak Karan ${ }^{1}$ (D) Chanchal Dey ${ }^{2}$ (I)
}

(c) Springer Nature Switzerland AG 2019

\begin{abstract}
Improved disturbance rejection behaviour with modified Smith predictor is reported here for controlling integrating first-order plus time delay processes. Due to location of a pole at origin, process is said to be integrating in nature. In addition, due to presence of considerable dead time, it is very difficult to obtain the desired output from such processes using conventional control technique. In practice, a good number of chemical processes (e.g. distillation, evaporation, combustion, drying etc.) are integrating as well as delay dominating in nature. To ascertain desirable close-loop response for processes with large dead time, Smith predictor is a renowned methodology due to its simplicity and efficacy. But, this technique fails to perform satisfactorily for integrating processes with time delay. A good alternative can be considered as modified Smith predictor. This technique involves more than one controller for achieving desirable servo as well as regulatory responses. To avoid the tuning complexity of controllers, our proposed scheme involves comparatively less number of controllers with relatively simple tuning guide line. Distinct feature of the proposed tuning scheme is that process overshoot can be restricted within acceptable limit as well as improved load recovery can also be achieved. Efficacy of the proposed scheme is substantiated through performance assessment as well as stability study in comparison with well-known modified Smith predictor based tuning relations is also reported.
\end{abstract}

Keywords Large dead time process · Dead time compensator · Modified Smith predictor · Integrating first-order plus time delay (FOPDT) process

\section{Introduction}

A process is said to be integrating in nature if any of its pole is located at origin. Integrating processes encompass an intrinsic non self-regulating nature and hence if they are disturbed from their equilibrium position, process output deviates continuously over a significant period of time. Hence controlling such processes in presence of considerable time delay is a challenging task [1]. During set point tracking and load recovery phases inappropriate control strategies as well as improper choice of tuning parameters for integrating processes often provide non-self-regulating behaviour [2]. Conventional control methodologies often fail to provide desired performance for processes with large dead time. Whereas the Smith predictor control technique [3] is an efficacious and broadly accepted scheme in such applications. But, conventional Smith predictor [3] technique fails to perform satisfactorily for integrating processes with large dead time due to their inherent nonself-regulating nature. Over the last few decades, a decent amount of research findings are reported [4-13, 18-25] towards modification and augmentation of the conventional Smith predictor [3]. Primarily Majhi and Atherton [11] proposed modified Smith predictor for integrating and unstable processes based on gain margin and phase margin criterion. Later, an extended version of modified

Somak Karan, somakkaran91@gmail.com; Chanchal Dey, cdaphy@caluniv.ac.in | ${ }^{1}$ Department of Applied Electronics and Instrumentation Engineering, Haldia Institute of Technology, Haldia, West Bengal, India. ${ }^{2}$ Instrumentation Engineering, Department of Applied Physics, University of Calcutta, Kolkata, West Bengal, India. 
Smith predictor is proposed by Rao et al. [19] with two controller structure dedicated for set point tracking and load rejection using direct synthesis method and optimal gain and phase margin criterion respectively for integrating and double integrating processes. Almost at the same time another approach was proposed by Shamsuzzoha and Lee [21] based on IMC filter structure to design PID controller for improved disturbance rejection for delay dominated processes. A similar work is also reported by Shamsuzzoha and Skogested [9] and the extended version of the work is reported by Shamsuzzoha [8] using single controller for stable and integrating processes. More recently, set point weighted IMC based PID controller designed by Wang et al. [22] has been widely accepted as modified Smith predictor for integrating processes with considerable time delay. Although modified Smith predictor for second-order process with non-minimum phase using two controllers is proposed by Uma and Rao [23] signifies enhanced responses for unstable processes. Alternative approach towards modified Smith predictor with sliding mode control for processes with large time delay is provided by Mehta and Kaya [24], and the similar strategy for unstable processes is also proposed by Mehta and Rojas [25]. Among these reported schemes [8, 9, 11, $19,21-25]$ majority of the modified Smith predictor mechanism involves three controllers and their tuning policy is also not quite straight forward in nature. Moreover, they usually fail to restrict the initial process overshoot during set point tracking and regulatory behaviour during load changes is also not satisfactory. Hence, there is a scope for finding out a modified Smith predictor structure with lesser complexity along with simplified tuning guideline which will be capable to provide satisfactory servo as well as regulatory responses.

Here, the proposed modified Smith predictor methodology involves only two controllers and their tuning mechanism is also quite straight forward in nature. Novelty of the proposed scheme is that a common tuning guideline is suggested for both the controllers present in feed-forward and feedback path. Effectiveness of the proposed scheme is verified through simulation study for well-known integrating FOPTD models resembling the behaviour of distillation column, chemical reactor; combustion chamber and evaporator [14]. To substantiate robustness of the proposed scheme considerable perturbation is incorporated in process parameters during simulation study. For quantitative performance estimation integral error indices (IAE, ISE) and integral time error indices (ITAE, ITSE) [15] are computed during each simulation study. Smoothness of the proposed scheme is also compared with others' reported modified Smith predictor [8, 9, 11, 19, 21, 22] by computing the value of total variation in control action (TV).

Discussion on the conventional and modified Smith predictor methodologies is provided in Sect. 2. Structure of our proposed tuning scheme is provided in Sect. 3 and the detailed tuning mechanism will be discussed in Sect. 4 . Stability and robustness issues are discussed in Sect. 5. Performance comparison is reported in Sect. 6 consisting of the proposed scheme along with other well-known modified Smith predictor schemes $[8,9,11,19,21,22]$ and at the end conclusion is provided in Sect. 7.

\section{Conventional and modified Smith predictor}

Primarily, Smith predictor technique is reported in [3] and later its enhanced form i.e. modified Smith predictor is suggested by Majhi and Atherton [11] as presented in Fig. 1. The technique proposed by Majhi and Atherton [11] is widely accepted related to dead time compensation for achieving improved close-loop responses during set point tracking and load rejection phases. Moreover, most
Fig. 1 Modified Smith predictor [11] based close-loop structure

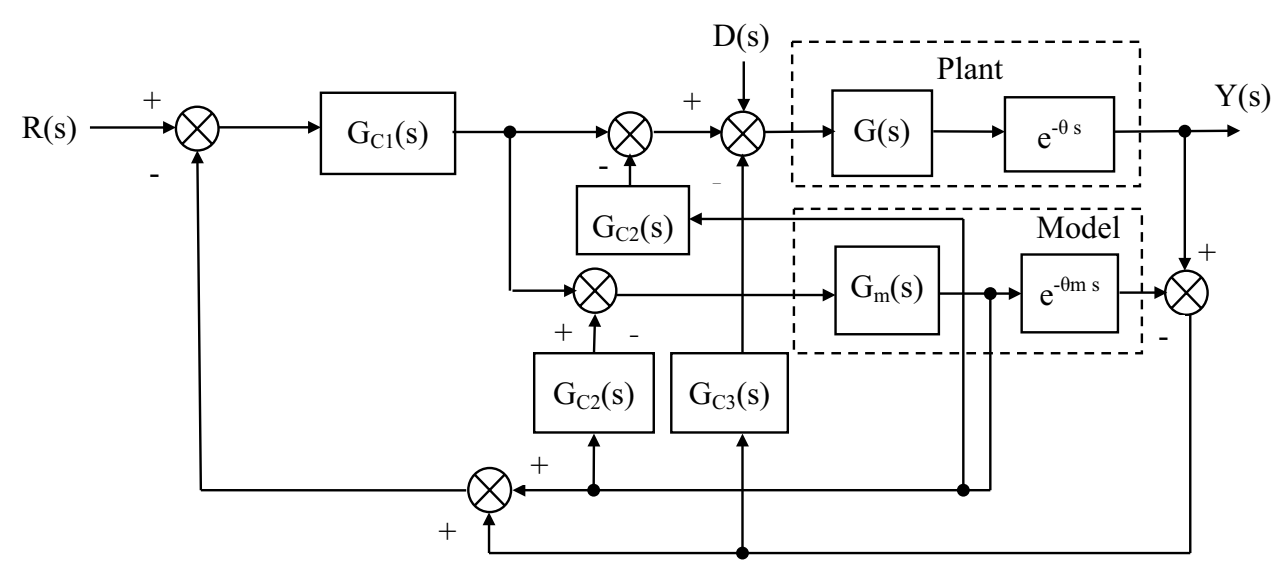


of the article $[10,18,19]$ are influenced by the proposed scheme [11] with more than one controller incorporated to obtain desired close-loop response. Modified Smith predictor [11] structure consists of three controllers, one controller is in the feed forward path and rest two controller are in feedback path. Feed-forward path controller $\mathrm{G}_{\mathrm{Cl}_{1}}(\mathrm{~s})$ is a $\mathrm{PI}$ controller to achieve improved set point tracking, whereas $\mathrm{G}_{\mathrm{C} 2}(\mathrm{~s})$ and $\mathrm{G}_{\mathrm{C} 3}(\mathrm{~s})$ are both $\mathrm{P}$ controllers located in the feedback path for eliminating the overshoot during set point tracking and curbing oscillations during load rejection phases respectively. In Fig. 1, process model is given by $G_{m}(s) e^{-\theta_{m} s}$ where $\theta_{m}$ is estimated dead time, and $D(s)$ is the disturbance signal introduced in feed-forward path.

Relation between the processes output and set point change is given by Eq. (1). Similarly, Eq. (2) represents the relation between process responses due to load variation.

$\frac{Y(s)}{R(s)}=\frac{G(s) \cdot G_{C 1}(s)}{1+G_{m}(s)\left(G_{C 1}(s)+G_{C 2}(s)\right)} e^{-\theta_{m} s}$ load recovery compared to conventional Smith predictor [3]. However, limitation of the modified Smith predictor [11] is that tuning approach for three controllers is not quite straight-forward.

\section{Proposed modified Smith predictor}

Proposed modified Smith predictor structure is depicted in Fig. 2, incorporating only two controllers. Out of these two controllers, $\mathrm{G}_{\mathrm{Cm} 1}(\mathrm{~s})$ is incorporated in feed-forward path for ensuring improved set point response and $\mathrm{G}_{\mathrm{Cm} 2}(\mathrm{~s})$ is in feedback path contributing towards enhanced load recovery. In the proposed modified Smith predictor, relation between process output $\left(\mathrm{Y}_{\mathrm{m}}\right)$ with respect to the set point change $\left(R_{m}\right)$ and load disturbance $\left(D_{m}\right)$ are given by Eqs. (3) and (4) respectively

$\frac{Y_{m}(s)}{R_{m}(s)}=\frac{G_{C m 1}(s) \cdot G_{m}(s)}{1+G_{C m 1}(s) G_{m}(s)} e^{-\theta_{m} s}$,

$\frac{Y(s)}{D(s)}=\frac{G(s) e^{-\theta_{m} s}}{1+G_{m}(s)\left(G_{C 2}(s)+G_{C 3}(s)\right)} \frac{1+G_{m}(s) \cdot\left(G_{C 1}(s)+G_{C 2}(s)-G_{C 1}(s) G_{C 3}(s) e^{-\theta m s}\right)}{1+G_{C 3}(s) G(s) e^{-\theta_{m} s}}$.

$\frac{Y_{m}(s)}{D_{m}(s)}=\frac{\left(1+G_{c m 1}(s) G_{m}(s)-G_{c m 1}(s) G_{m}(s) e^{-\theta_{m} s}\right) G_{m}(s) e^{-\theta_{m} s}}{\left(1+G_{c m 1}(s) G_{m}(s)\right)\left(1+G_{c m 2}(s) G_{m}(s) e^{-\theta_{m} s}\right)}$.

Here, $\mathrm{G}_{\mathrm{Cm} 1}(\mathrm{~s})$ is $\mathrm{PI}$ controller which is tuned for ensuring improved set point tracking and $\mathrm{G}_{\mathrm{Cm} 2}(\mathrm{~s})$ is $\mathrm{PD}$ controller designed targeted towards eliminating oscillations caused due to uncertain disturbances. Instead of three controllers present in modified Smith predictor [11], the proposed model with only two controllers is capable to provide enhanced close-loop performance in terms of set point tracking and load rejection. Set point weighting scheme provides servo response without having any overshoot,
Fig. 2 Proposed modified Smith predictor based closeloop structure

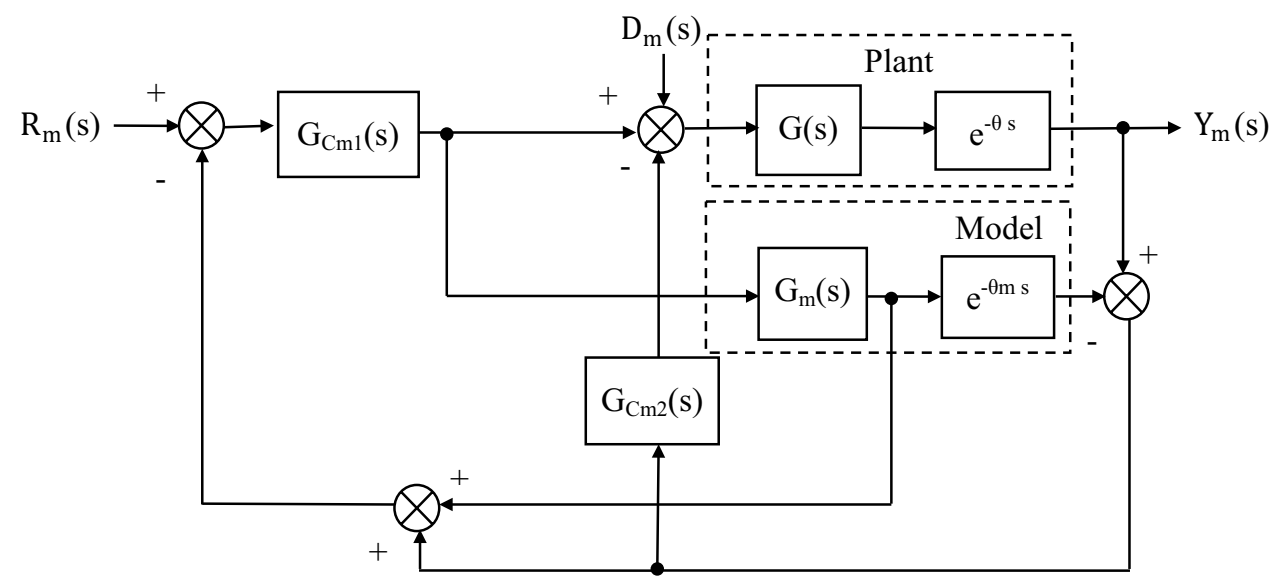

SN Applied Sciences 
i.e. it helps to eliminate one controller from the design of modified Smith predictor [11] without sacrificing closeloop performance. Here, tuning complexity is reduced with simpler tuning approaches and lesser number of controllers. As a result, we can expect that an improved set point response as well as quicker disturbance rejection may be achieved in case of our proposed modified Smith predictor compared to others reported modified Smith predictor methodologies $[8,9,11,19,21,22]$. Expression of $\mathrm{G}_{\mathrm{Cm} 1}(\mathrm{~s})$ and $\mathrm{G}_{\mathrm{Cm} 2}(\mathrm{~s})$ of the proposed modified Smith predictor controller are given by the following relations:

$\mathrm{G}_{\mathrm{Cm} 1}(\mathrm{~s})=\mathrm{K}_{\mathrm{P}}\left(1+\frac{1}{\mathrm{~T}_{\mathrm{i}} \mathrm{s}}\right)$,

$\mathrm{G}_{\mathrm{Cm} 2}(\mathrm{~s})=\gamma \mathrm{K}_{\mathrm{p}}\left(1+\mathrm{T}_{\mathrm{d}} \mathrm{s}\right)$.

In Eq. (5), $\mathrm{G}_{\mathrm{Cm} 1}(\mathrm{~s})$ is a PI controller where $\mathrm{K}_{\mathrm{p}}$ is the proportional gain and $T_{i}$ is the integral time. $G_{\mathrm{Cm} 2}(s)$ is a $P D$ controller which contains derivative time $T_{d}$ and an additional tuning parameter $\gamma$ is incorporated with the proportional term $\mathrm{K}_{\mathrm{p}}$ as given by Eq. (6). Here, it is to mention that same proportional gain $\mathrm{K}_{\mathrm{p}}$ is considered for both the controllers i.e. $\mathrm{G}_{\mathrm{Cm} 1}(\mathrm{~s})$ and $\mathrm{G}_{\mathrm{Cm} 2}(\mathrm{~s})$. Additional tuning parameter $\gamma$ is obtained from Routh stability analysis [16] of Eq. (4) relating process output to disturbance input to ensure enhanced load recovery.

Now, we find out the expression of our proposed modified Smith predictor for a typical integrating FOPDT model as given by Eq. (7) where $G(s)$ is the actual transfer function and $G_{m}(s)$ is its identified model. $K_{m}$ is the open-loop process gain and $\theta_{m}$ is the dead time of the process.

$\mathrm{G}(\mathrm{s}) \mathrm{e}^{-\theta s}=\mathrm{G}_{\mathrm{m}}(\mathrm{s}) \mathrm{e}^{-\theta_{\mathrm{m}} \mathrm{s}}=\frac{\mathrm{K}_{\mathrm{m}}}{\mathrm{s}} \mathrm{e}^{-\theta_{\mathrm{m}} \mathrm{s}}$.

Location of pole at the origin signifies non-self-regulating nature of the process as given by Eq. (7). As per the tuning guideline by Majhi and Atherton [11], unity proportional gain $\left(\mathrm{K}_{\mathrm{p}}\right)$ and a smaller value of integral time $\left(\mathrm{T}_{\mathrm{i}}\right)$ are suggested for integrating FOPTD process. Here, in our proposed scheme to restrict the initial overshoot, set point weighting [19] mechanism is incorporated in PI controller structure (Eq. 5) present in the feed-forward path of the modified Smith predictor.

$\mathrm{G}_{\mathrm{cm} 1}^{\prime}(\mathrm{s})=\mathrm{K}_{\mathrm{p}}\left[\left\{\varepsilon \cdot \mathrm{R}_{\mathrm{m}}(\mathrm{s})-\mathrm{Y}_{\mathrm{m}}(\mathrm{s})\right\}+\frac{1}{\mathrm{~T}_{\mathrm{i}} \mathrm{s}}\right]$.

Here, the value of the weighting factor $(\varepsilon<1)$ is multiplied with the set value $\left(R_{m}(s)\right)$ and the resulting controller $\mathrm{G}_{\mathrm{cm} 1}^{\prime}(\mathrm{s})$ is given by Eq. (8).

\section{Tuning guideline of the proposed scheme}

Tuning guideline for both the controllers $\mathrm{G}_{\mathrm{Cm} 1}(\mathrm{~s})$ and $\mathrm{G}_{\mathrm{Cm} 2}(\mathrm{~s})$ of the proposed scheme along with its additional tuning parameter $\gamma$ is provided here. As mentioned in the previous section we adopted the tuning guideline as suggested by Majhi and Atherton [11], proportional gain for $\mathrm{G}_{\mathrm{Cm} 1}(\mathrm{~s})$ is considered to be unity i.e. $\mathrm{K}_{\mathrm{p}}=1$ and smaller value of integral time i.e. $T_{i}=0.1 \mathrm{~s}$. The disturbance suppressing controller $\mathrm{G}_{\mathrm{Cm} 2}(\mathrm{~s})$ is a PD controller whose proportional gain is $\gamma \mathrm{K}_{p}$ and its derivative time is $T_{d}$. Here, the choice of $T_{d}$ is crucial as it plays important role in eliminating undesired oscillation during load recovery phases.

Based on extensive simulation study it is found that enhanced load rejection performance can be obtained for

$\mathrm{T}_{\mathrm{d}}=\frac{\theta_{\mathrm{m}}}{4}$.

Transfer function relating the process output due to load change is given by Eq. (4). Hence, the characteristic equation for load rejection transfer function (Eq. 4) is defined as

$1+\mathrm{G}_{\mathrm{Cm} 2}(\mathrm{~s}) \mathrm{G}_{\mathrm{m}}(\mathrm{s}) \mathrm{e}^{-\theta_{\mathrm{m}} \mathrm{s}}=0$.

Now, substituting the values of $\mathrm{G}_{\mathrm{Cm} 2}$ (s) from Eq. (6), $G_{m}(s)$ from Eq. (7), and $T_{d}$ from Eq. (9) in Eq. (10) we get

$1+\gamma \mathrm{K}_{\mathrm{p}}\left(1+\frac{\theta_{\mathrm{m}}}{4} \mathrm{~s}\right) \cdot \frac{\mathrm{K}_{\mathrm{m}}}{\mathrm{s}} \cdot \mathrm{e}^{-\theta_{\mathrm{m}} \mathrm{s}}=0$.

Time delay part $\mathrm{e}^{-\theta_{\mathrm{m}} \mathrm{s}}$ is approximated using the firstorder Pade's approximation [17] and the resulting expression is given by Eq. (12)

$4 s+K_{m} \cdot \gamma \cdot K_{p}\left(4+\theta_{m} s\right) \frac{-0.5 \theta_{m} s+1}{0.5 \theta_{m} s+1}=0$.

Now, Routh array is formed from Eq. (12) and to ensure stability, first element of each row of the Routh array should be positive as given by the following relations

$2 \theta-2 \gamma \mathrm{K}_{\mathrm{p}} \theta_{\mathrm{m}}^{2} \mathrm{~K}_{\mathrm{p}}>0$,

$4\left(1-\gamma \theta_{m} K_{p} K_{m}\right)>0$,

$16 \gamma \mathrm{K}_{\mathrm{p}} \mathrm{K}_{\mathrm{m}}>0$.

From Eqs. (13) and (14) lower limit of $\gamma$ may be obtained to ensure stability. Similarly, upper limit of $\gamma$ can also be found from Eq. (15) and hence the resulting boundary of $\gamma$ with ensured stability is given by Eq. (16)

$0<\gamma<\frac{1}{\theta_{\mathrm{m}} \mathrm{K}_{\mathrm{m}} \mathrm{K}_{\mathrm{p}}}$. 
Here, it is to mention that the value of $\gamma$ as suggested by Majhi and Atherton [11] also conforms the value as provided by Eq. (16). According to the guideline of Majhi and Atherton [11], based on phase margin and gain margin criterion, the expression of $\gamma$ is given by the following relation

$\gamma=\frac{0.5235}{\theta_{\mathrm{m}} \mathrm{K}_{\mathrm{m}} \mathrm{K}_{\mathrm{p}}}$.

Here, the value of $\gamma$ given by Eq. (17) lies almost at the middle of the range as given by Eq. (16).

\section{Stability and robustness}

Suitability of a controller is judged by its stability and robustness feature during close-loop control along with its performance indices. In case of Smith predictor control technique [3] proper estimation of plant model is very crucial. But, in practice uncertainties are always present in process model. Here, in case of integrating FOPTD models uncertainties are there in the form of process gain and time delay. Now, robust stability analysis is performed using well-known and widely accepted small gain theorem for multiplicative uncertainty represented by $M-\Delta$ structure [18]. The close-loop system is said to be robustly stable if and only if the constraint [18] satisfies the small gain theorem as given by Eq. (18),

i.e. $\left\|\Delta_{m}(j \omega) C(j \omega)\right\|<1$ for $\forall \omega(-\infty, \infty)$

where $C(s=j \omega)$ is the complementary sensitivity function and $\Delta_{m}(s=j \omega)$ is the bound on the process multiplicative uncertainty. Complementary sensitivity function for the proposed scheme can be defined as

$C(j \omega)=\frac{G_{c m 1} G_{m} e^{-\theta s}}{1+\left(G_{c m 2}+G_{c m 1}\right) G_{m}}$.

Now, for the integrating FOPTD model along with its controllers' parameters, complementary sensitivity function can be written as,
Here $G(j \omega) e^{-\theta s}$ is the actual process and $G_{m}(j \omega) e^{-\theta_{m} s}$ is the estimated process model. If uncertainty exists in process time delay, then the tuning parameter must be so selected that

$C(j \omega)_{\infty}<\frac{1}{\left|e^{-\Delta \theta s}-1\right|}$.

If the uncertainty exists in process gain, then the tuning parameter must be chosen in such a way that

$\mathrm{C}(\mathrm{j} \omega)_{\infty}<\frac{1}{\frac{\left|\Delta \mathrm{K}_{\mathrm{m}}\right|}{\mathrm{K}_{\mathrm{m}}}}$.

Moreover, if the uncertainty exists in process gain and time delay simultaneously, then the tuning parameter must be chosen as

$\mathrm{C}(\mathrm{j} \omega)_{\infty}<\frac{1}{\left|\left(\frac{\Delta \mathrm{K}_{\mathrm{m}}}{\mathrm{K}_{\mathrm{m}}}+1\right) \mathrm{e}^{-\Delta \theta \mathrm{s}}-1\right|}$.

Therefore, the sensitivity and complementary sensitivity function must satisfy the condition for robust performance of close-loop system [18] as given by Eq. (25)

$\Delta_{\mathrm{m}}(\mathrm{j} \omega) \mathrm{C}(\mathrm{j} \omega)+\mathrm{w}_{\mathrm{m}}(1-\mathrm{C}(\mathrm{j} \omega))<1$

where $w_{m}$ is considered as the uncertainty bound on the sensitivity function $s(j \omega)=1-C(j \omega)$.

\section{Simulation results}

In simulation study, performance of the proposed scheme is evaluated during set point tracking and load recovery phases for three well-known integrating FOPTD models. Robustness of the proposed scheme is tested with more than $+10 \%$ perturbations in dead time and open-loop gain of the process models. Close-loop performance of the proposed scheme during nominal and perturbed condition is compared with reputed modified Smith predictor

$C(j \omega)=\frac{-0.05 K_{m} \theta_{m}(j \omega)^{2}+\left(0.1 K_{m}-0.5 K_{m} \theta_{m}\right) j \omega+K_{m}}{0.05 \theta_{m}(j \omega)^{3}+\left(0.1-0.05 K_{m} \theta_{m}\right)(j \omega)^{2}+\left(0.1 K_{m}-0.5 K_{m} \theta_{m}\right) j \omega+K_{m}}$.

From Eq. (18), bound on complementary sensitivity function can be represented as

$\Delta_{m}(j \omega)<\left|\frac{G(j \omega) e^{-\theta s}-G_{m}(j \omega) e^{-\theta_{m} s}}{G_{m}(j \omega) e^{-\theta_{m} s}}\right|$. schemes reported by Shamsuzzoha [8], Shamsuzzoha and Skogested [9], Majhi and Atherton [11], Rao et al. [19], Shamsuzzoha and Lee [21], and Wang et al. [22]. During simulation study, initially step set point change is provided and once the process reaches the steady state condition, pulse like load disturbance signal is introduced at the input to the process. To have quantitative estimation rise time $\left(t_{r}\right)$, percentage peak overshoot $\left(\% M_{p}\right)$, settling time 
$\left(t_{s}\right)$, integral error indices (IAE and ISE) as well as integral time error indices (ITAE and ITSE) are calculated. In addition, to estimate the smoothness in control action, total variation in control action (TV) is also computed for each case. Moreover, external interference in terms of noise is incorporated in the process output for all process models with noise power of 0.001 (Fig. 3) to evaluate close-loop response in practice. Stability and robustness of three integrating FOPTD models in terms of perturbation in process gain $\left(\Delta \mathrm{K}_{\mathrm{m}}\right)$ and time delay $(\Delta \theta)$ with respect to complementary sensitivity function $C(j \omega)$ as given by Eqs. (22), (23) and (24) are estimated in Table 2.

\subsection{Model I}

We consider a well-known integrating FOPDT model reported in [11, 19] as Model I, given by the following relation

$G_{p 1}(s)=\frac{1}{s} e^{-5 s}$

Here, the FOPTD model has time delay of $\theta_{\mathrm{m}}=5 \mathrm{~s}$ with open loop gain $\mathrm{K}_{\mathrm{m}}=1$. Performance based comparison is made with modified Smith predictor setting reported by Rao et al. [19], and Majhi and Atherton [11]. For the proposed scheme, expression of the two controllers $\mathrm{G}_{\mathrm{Cm} 1}(\mathrm{~s})$ and $\mathrm{G}_{\mathrm{Cm} 2}(\mathrm{~s})$ are provided in Table 1. Close-loop responses along with effective control action for the nominal model (Eq. 26) during set point tracking and load rejection phases are depicted in Fig. $4 a$, c where solid black line represents the response of the proposed setting and dashed blue line and dotted red line represent responses reported by Rao et al. [19], and Majhi and Atherton [11] respectively. To evaluate performance robustness of all the reported controllers, responses and the corresponding control action for the perturbed model $\hat{G}_{\mathrm{p} 1}(\mathrm{~s})$ with $+10 \%$ perturbation as given by Eq. (27) are depicted in Fig. $4 \mathrm{~b}, \mathrm{~d}$. Magnitude of complementary sensitivity function versus frequency plot for integrating process (Model I) is shown in Fig. 5 due to positive perturbations in process gain $\left(\Delta \mathrm{K}_{\mathrm{m}}\right)$ and time delay $(\Delta \theta)$. Robustness of the proposed controller is evaluated in presence of noise signal which is shown in Fig. 3. Close-loop responses and corresponding control action in presence of noise signal are depicted in Fig. 6a, $b$, respectively for the nominal process model as given by Eq. (26). Robust stability analysis is performed using small gain theorem [18] for the proposed scheme as provided in Table 2. Here, it is to note that due to considerably large dead time value, relatively smaller perturbation is allowed

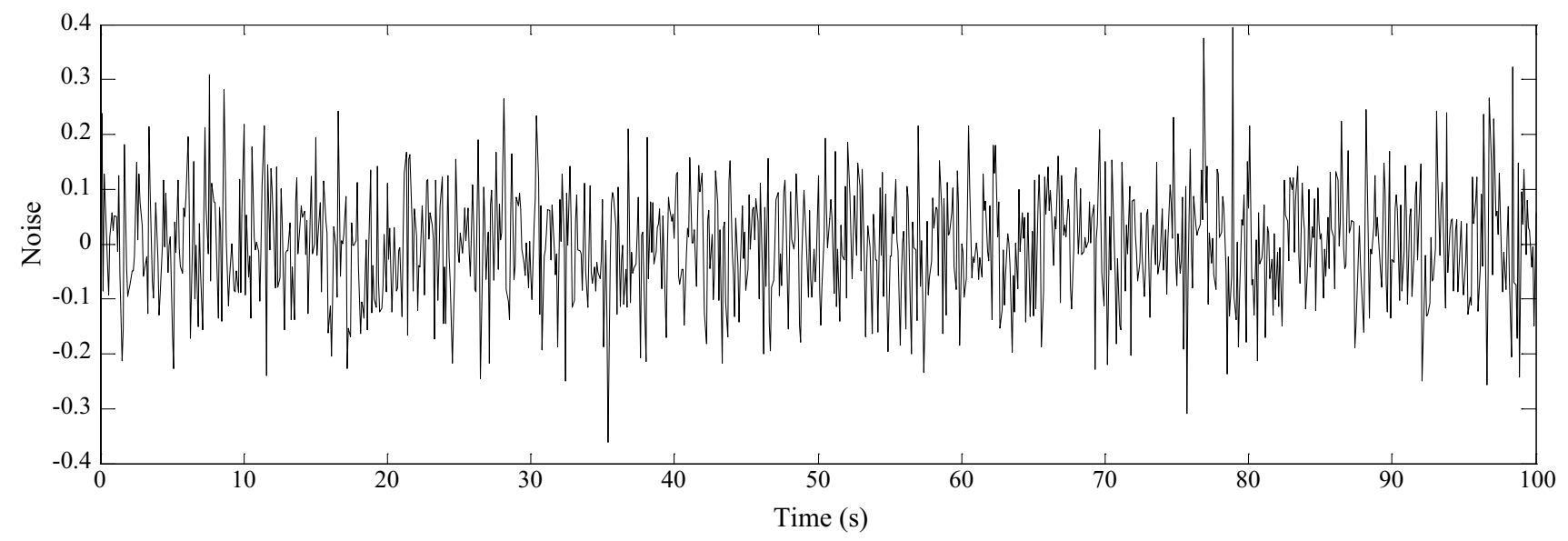

Fig. 3 Noise signal with power of 0.001 incorporated in the output for all process models (Model I-III)

Table 1 Tuning parameters of the proposed modified Smith predictor for all three integrating FOPTD process models (Model I-III)

\begin{tabular}{|c|c|c|c|c|c|c|c|c|c|c|}
\hline \multirow[t]{2}{*}{ Model } & \multirow[t]{2}{*}{ Transfer function } & \multicolumn{3}{|c|}{$\mathrm{G}_{\mathrm{cm} 1}$} & \multicolumn{3}{|c|}{$\mathrm{G}_{\mathrm{cm} 2}$} & \multirow[t]{2}{*}{$\mathrm{G}_{\mathrm{cm} 1}$} & \multirow[t]{2}{*}{$\mathrm{G}_{\mathrm{cm} 2}$} & \multirow[t]{2}{*}{ Stability range of $\gamma$} \\
\hline & & $\mathrm{K}_{\mathrm{p}}$ & $\mathrm{T}_{\mathrm{i}}$ & $\varepsilon$ & $\mathrm{K}_{\mathrm{p}}$ & $\mathrm{T}_{\mathrm{d}}$ & $\gamma$ & & & \\
\hline I & $\frac{1}{s} e^{-5 s}[11,19]$ & 1 & 0.1 & 0.9 & 1 & 1.25 & 0.11 & $\frac{0.09 s+1}{0.1 \mathrm{~s}}$ & $0.11+0.14 s$ & $0<\gamma<0.20$ \\
\hline II & $\frac{0.2}{s} e^{-7.4 s}[21,22]$ & & & 0.5 & & 1.85 & 0.35 & $\frac{0.05 \mathrm{~s}+1}{0.1 \mathrm{~s}}$ & $0.35+0.65 s$ & $0<\gamma<0.67$ \\
\hline III & $\frac{1}{s} e^{-s}[8,9]$ & & & 0.9 & & 0.25 & 0.52 & $\frac{0.09 \mathrm{~s}+1}{0.1 \mathrm{~s}}$ & $0.52+0.13 s$ & $0<\gamma<1.00$ \\
\hline
\end{tabular}




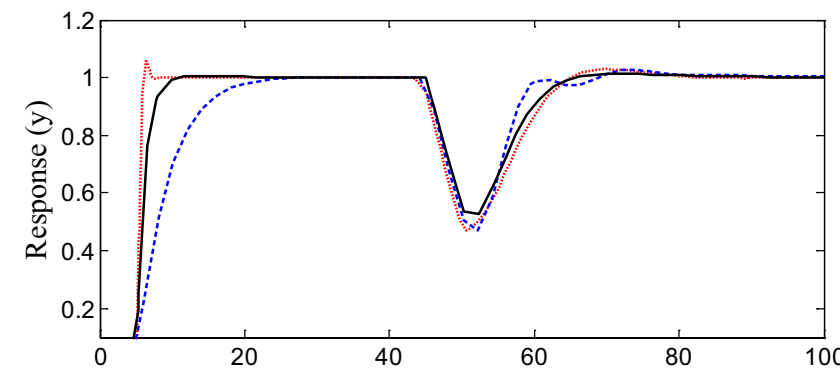

(a)

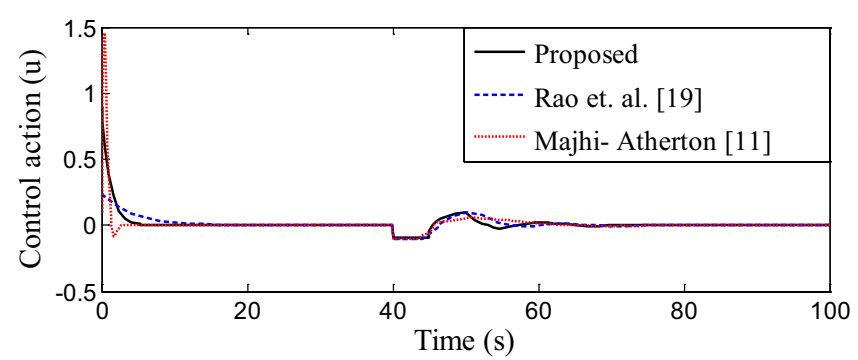

(c)

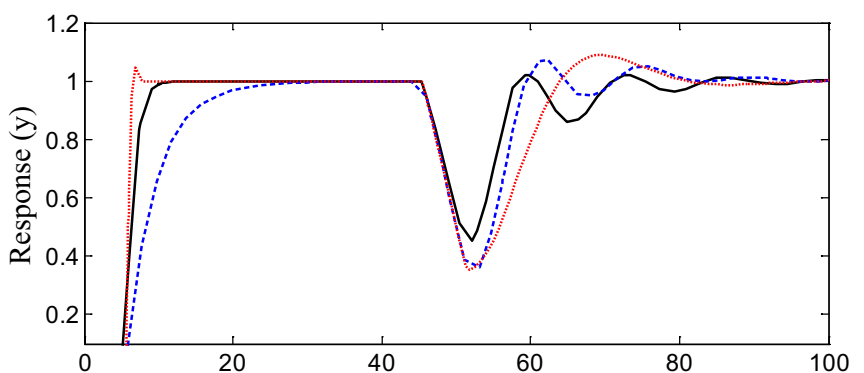

(b)

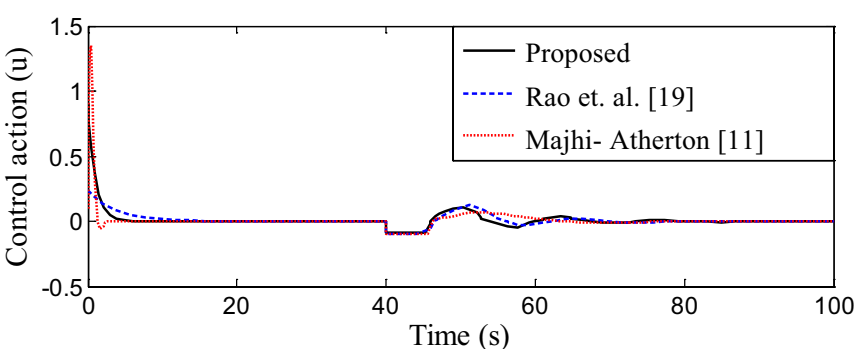

(d)

Nominal model I

Perturbed model I

Fig. 4 Set point tracking and load rejection responses along with control actions for nominal and perturbed Model I

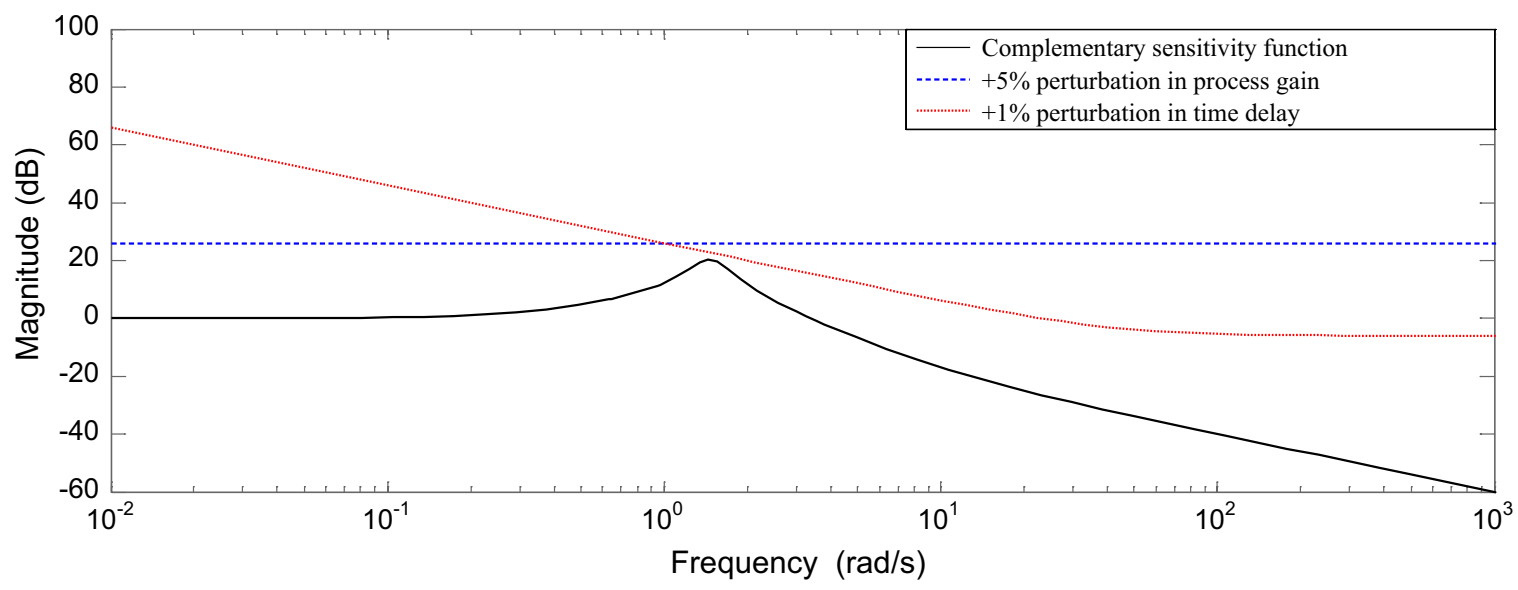

Fig. 5 Magnitude plot of complementary sensitivity function $\mathrm{C}(\mathrm{j} \omega)$ with $+5 \%$ perturbation in process gain $\Delta \mathrm{K}_{\mathrm{m}}=0.05$ and $+1 \%$ perturbation in time delay $\Delta \theta=0.05$ for Model I

in case of dead time without destabilizing the process response.

$\hat{\mathrm{G}}_{\mathrm{p} 1}(\mathrm{~s})=\frac{1.1}{\mathrm{~s}} \mathrm{e}^{-5.5 \mathrm{~s}}$.

Performance indices during servo and regulatory responses with nominal and perturbed form of Model I is provided in Tables 3 and 4 respectively. Here, it is to note that without compromising the rise time $\left(t_{r}\right)$ overshoot is completely eliminated in the proposed scheme as well as faster load recovery is also found compared to the settings reported by Rao et al. [19], and Majhi and Atherton [11]. Set point weighting $(\varepsilon=0.9)$ technique is employed here to restrict initial process overshoot. 


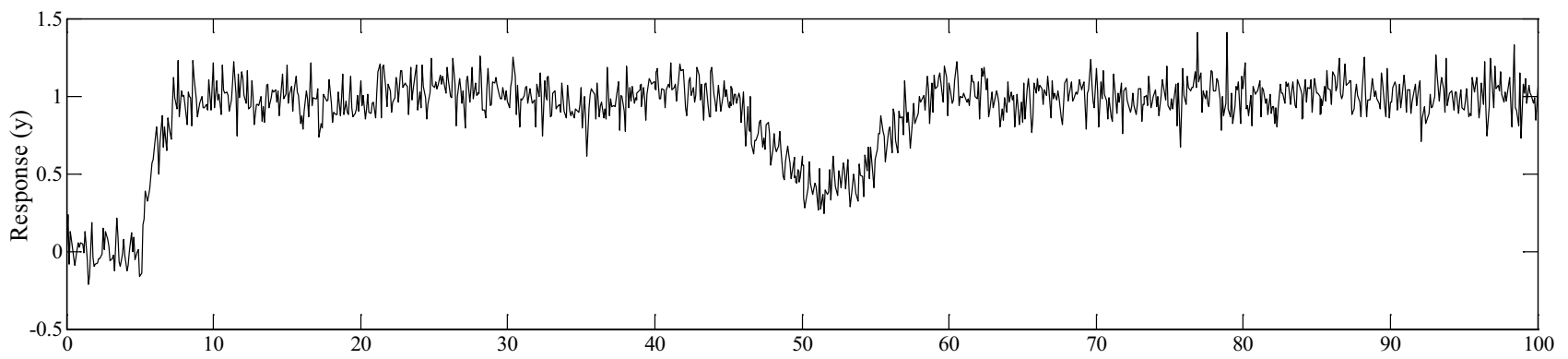

(a)

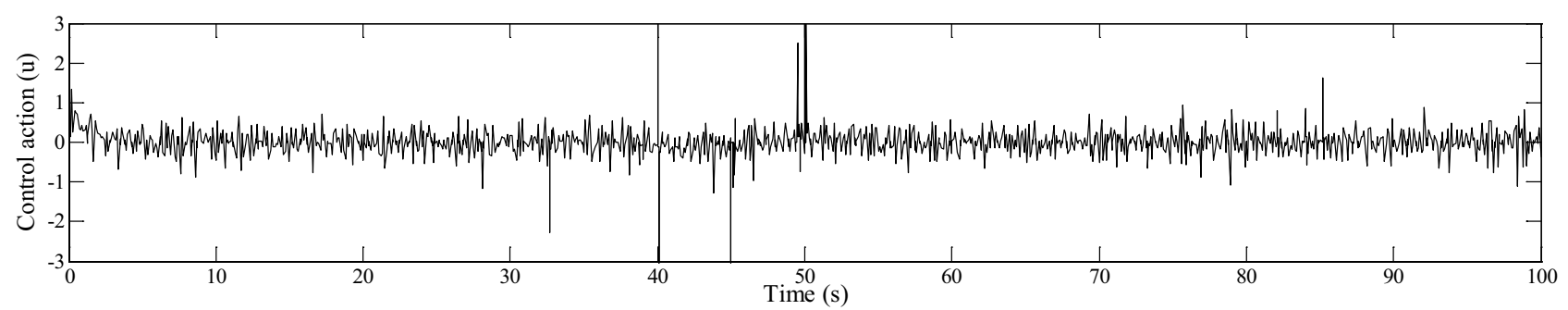

(b)

Fig. 6 Set point tracking and load rejection response along with control action for nominal Model I in presence of noise signal for the proposed controller

Table 2 Robust stability analysis of the proposed scheme in presence of uncertainty or perturbation for integrating FOPTD processes (Model I-III) in terms of process gain $\Delta \mathrm{K}_{\mathrm{m}}$ and time delay $\Delta \theta$ using small gain theorem

\begin{tabular}{llllll}
\hline Process model & $\begin{array}{l}\text { Complementary sensi- } \\
\text { tivity function } \\
\mathrm{C}(\mathrm{j} \omega)\end{array}$ & $\begin{array}{l}\text { Perturbation of } \\
\text { process gain }\left(\Delta \mathrm{K}_{\mathrm{m}}\right)\end{array}$ & $\begin{array}{l}\text { Robust stability condition } \\
\text { for perturbed process gain }\end{array}$ & $\begin{array}{l}\text { Perturbation of } \\
\text { time delay }(\Delta \theta)\end{array}$ & $\begin{array}{l}\text { Robust stability condi- } \\
\text { tion for perturbed time } \\
\text { delay }\end{array}$ \\
\hline Model I & $\frac{-0.25 j \omega^{2}-2.4 j \omega+1}{0.25 j \omega^{3}+0.35 j \omega^{2}+0.35 j \omega+1}$ & $0.05(+5 \%)$ & $\mathrm{C}(\mathrm{j} \omega)_{\infty}<\frac{1}{0.05}$ & $0.05(+1 \%)$ & $\mathrm{C}(\mathrm{j} \omega)_{\infty}<\frac{\mathrm{j} 0.025 \omega+1}{-\mathrm{j} 0.05 \omega}$ \\
Model II & $\frac{-0.074 \mathrm{j} \omega^{2}-0.72 \mathrm{j} \omega+0.2}{0.37 \mathrm{j} \omega^{3}+0.17 \mathrm{j} \omega^{2}+0.76 \mathrm{j} \omega+0.2}$ & $0.02(+10 \%)$ & $\mathrm{C}(\mathrm{j} \omega)_{\infty}<\frac{1}{0.1}$ & $0.07(+1 \%)$ & $\mathrm{C}(\mathrm{j} \omega)_{\infty}<\frac{\mathrm{j} 0.35 \omega+1}{-j 0.7 \omega}$ \\
Model III & $\frac{-0.05 \mathrm{j} \omega^{2}-0.4 \mathrm{j} \omega+1}{0.05 j \omega^{3}-0.05 \mathrm{j} \omega^{2}-0.4 j \omega+1}$ & $0.5(+50 \%)$ & $\mathrm{C}(\mathrm{j} \omega)_{\infty}<\frac{1}{0.5}$ & $0.35(+35 \%)$ & $\mathrm{C}(\mathrm{j} \omega)_{\infty}<\frac{\mathrm{j} 0.175 \omega+1}{-\mathrm{j} 35 \omega}$ \\
\hline
\end{tabular}

Table 3 Performance analysis during servo responses for nominal and perturbed integrating FOPTD processes (Model I-III)

\begin{tabular}{|c|c|c|c|c|c|c|c|c|c|c|}
\hline \multirow[t]{2}{*}{ Nominal model } & \multirow[t]{2}{*}{ Scheme } & \multicolumn{4}{|c|}{ Nominal } & \multirow[t]{2}{*}{ Perturbed model } & \multicolumn{4}{|c|}{ Perturbed } \\
\hline & & TV & $t_{r}(s)$ & $M_{p}(\%)$ & $t_{s}(s)$ & & TV & $t_{r}(s)$ & $M_{p}(\%)$ & $t_{s}(s)$ \\
\hline \multirow[t]{3}{*}{ Model I } & Proposed & 2.02 & 5.96 & 0 & 10.99 & \multirow{3}{*}{$\begin{array}{l}\frac{1.1}{s} e^{-5.5 s} \\
(+10 \% \text { Perturbation) }\end{array}$} & 2.40 & 6.40 & 0 & 11.29 \\
\hline & Rao et al. [19] & 2.26 & 8.05 & 0 & 27.49 & & 2.50 & 8.41 & 0 & 30.48 \\
\hline & Majhi-Atheron [11] & 2.16 & 5.44 & 5.8 & 9.11 & & 2.35 & 5.93 & 3.8 & 9.41 \\
\hline \multirow[t]{3}{*}{ Model II } & Proposed & 8.33 & 15.03 & 6.6 & 55.11 & \multirow{3}{*}{$\begin{array}{l}\frac{0.24}{\mathrm{~s}} \mathrm{e}^{-8.88 \mathrm{~s}} \\
(+20 \% \text { Perturbation) }\end{array}$} & 8.63 & 13.23 & 3.10 & 55.78 \\
\hline & Wang et al. [22] & 8.75 & 16.14 & 12 & 152 & & 9.13 & 13.74 & 10.4 & 154.70 \\
\hline & Shamsuzzoha-Lee [21] & 8.48 & 16.18 & 8.90 & 154 & & 8.99 & 13.64 & 7.5 & 167.90 \\
\hline \multirow[t]{3}{*}{ Model III } & Proposed & 1.39 & 2.29 & 0 & 7.73 & \multirow{3}{*}{$\begin{array}{l}\frac{1.1}{s-1} e^{-1.1 s} \\
(+10 \% \text { Perturbation) }\end{array}$} & 1.40 & 2.42 & 0 & 9.62 \\
\hline & Shamsuzzoha [8] & 1.78 & 4.24 & 7.30 & 29.06 & & 2.05 & 4.27 & 6.40 & 29.36 \\
\hline & Shamsuzzoha-Skogested [9] & 2.11 & 2.89 & 38.60 & 30.24 & & 2.26 & 2.92 & 38.89 & 31.05 \\
\hline
\end{tabular}


Table 4 Performance analysis of regulatory responses for nominal and perturbed integrating FOPTD processes (Model I-III)

\begin{tabular}{|c|c|c|c|c|c|c|c|c|c|c|}
\hline \multirow[t]{2}{*}{ Nominal model } & \multirow[t]{2}{*}{ Scheme } & \multicolumn{4}{|c|}{ Nominal } & \multirow[t]{2}{*}{ Perturbed model } & \multicolumn{4}{|c|}{ Perturbed } \\
\hline & & IAE & ITAE & ISE & ITSE & & IAE & ITAE & ISE & ITSE \\
\hline \multirow[t]{3}{*}{ Model I } & Proposed & 1.84 & 49.09 & 0.54 & 2.01 & $\begin{array}{l}\frac{1.1}{s} e^{-5.5 s} \\
(+10 \% \text { Perturbation) }\end{array}$ & 2.03 & 54.06 & 0.58 & 2.08 \\
\hline & Rao et al. [19] & 6.18 & 142.40 & 2.25 & 14.52 & & 6.27 & 148.70 & 2.18 & 16.61 \\
\hline & Majhi-Atherton [11] & 6.84 & 147.30 & 2.76 & 15.25 & & 6.96 & 156.68 & 2.78 & 17.26 \\
\hline \multirow[t]{3}{*}{ Model II } & Proposed & 8.53 & 461.70 & 3.48 & 34.77 & $\begin{array}{l}\frac{0.24}{s} e^{-8.88 s} \\
(+20 \% \text { Perturbation })\end{array}$ & 9.22 & 498.30 & 3.86 & 38.63 \\
\hline & Wang et al. [22] & 24.53 & 3340 & 4.75 & 528 & & 26.58 & 3445 & 5.46 & 549.60 \\
\hline & Shamsuzzoha-Lee [21] & 25.82 & 3796 & 4.99 & 601.80 & & 27.87 & 3903 & 5.67 & 618.10 \\
\hline \multirow[t]{3}{*}{ Model III } & Proposed & 1.36 & 14.42 & 0.52 & 0.67 & $\begin{array}{l}\frac{1.1}{s} e^{-1.1 s} \\
(+10 \% \text { Perturbation) }\end{array}$ & 1.48 & 15.14 & 0.56 & 0.70 \\
\hline & Shamsuzzoha [8] & 5.13 & 84.98 & 1.51 & 9.10 & & 5.39 & 88.19 & 1.64 & 9.66 \\
\hline & Shamsuzzoha-Skogested [9] & 7.72 & 143.20 & 1.99 & 21.66 & & 7.90 & 145.90 & 2.08 & 22.70 \\
\hline
\end{tabular}

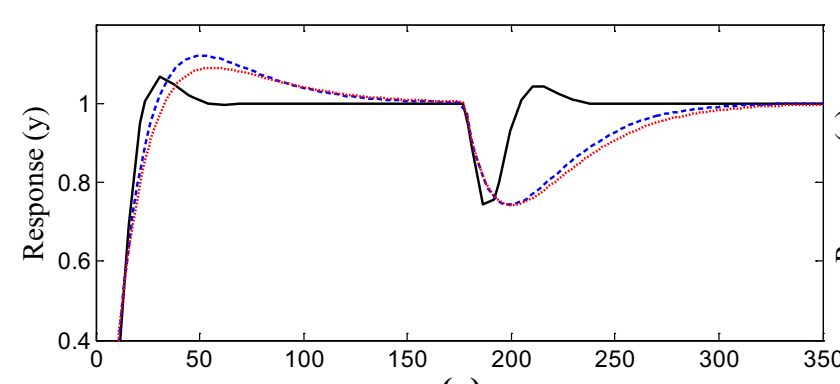

(a)

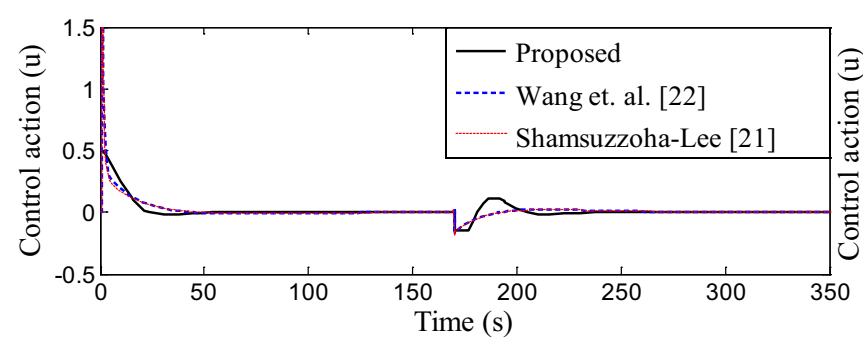

(c)

Nominal model II

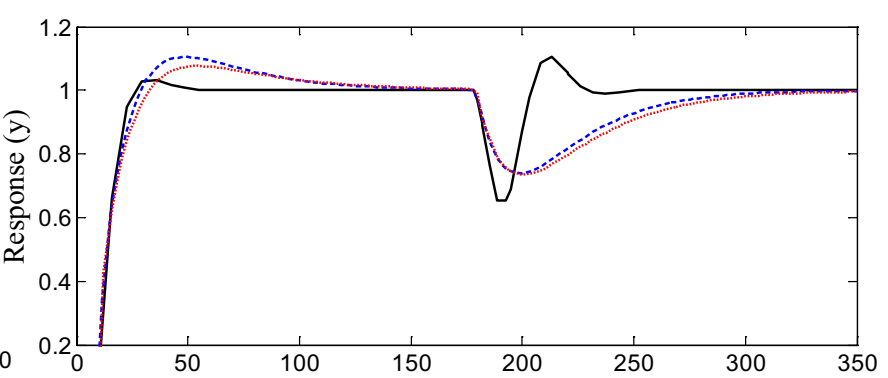

(b)

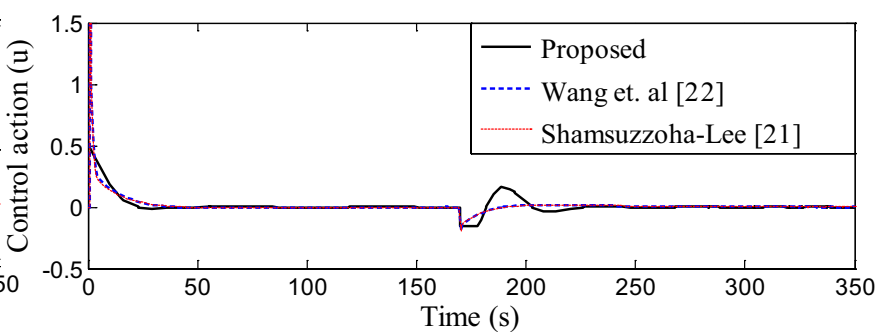

(d)

Fig. 7 Set point tracking and load rejection responses along with control actions for nominal and perturbed Model II

\subsection{Model II}

We consider another integrating FOPTD process model (Model II) as given by Eq. (28) which represents the behaviour of a distillation column as given by

$\mathrm{G}_{\mathrm{p} 2}(\mathrm{~s})=\frac{0.2}{\mathrm{~s}} \mathrm{e}^{-7.4 \mathrm{~s}}$.

This marginally stable FOPTD model is reported by Shamsuzzoha and Lee [21], and Wang et al. [22]. For Model
II settings of $\mathrm{G}_{\mathrm{Cm} 1}(\mathrm{~s})$ and $\mathrm{G}_{\mathrm{Cm} 2}(\mathrm{~s})$ controllers are provided in Table 1. Close-loop responses for nominal model during set point change and load variation along with their effective corresponding control action are depicted in Fig. 7a, c. Performance evaluation is also done for the perturbed model $\hat{\mathrm{G}}_{\mathrm{p} 2}(\mathrm{~s})$ with $+20 \%$ perturbation as given by Eq. (29) to verify the robustness of the reported controllers. Moreover, the close-loop response associated with noise signal (Fig. 3) is depicted in terms of close-loop responses and control action for nominal process model (Eq. 28) in Fig. 8a, 


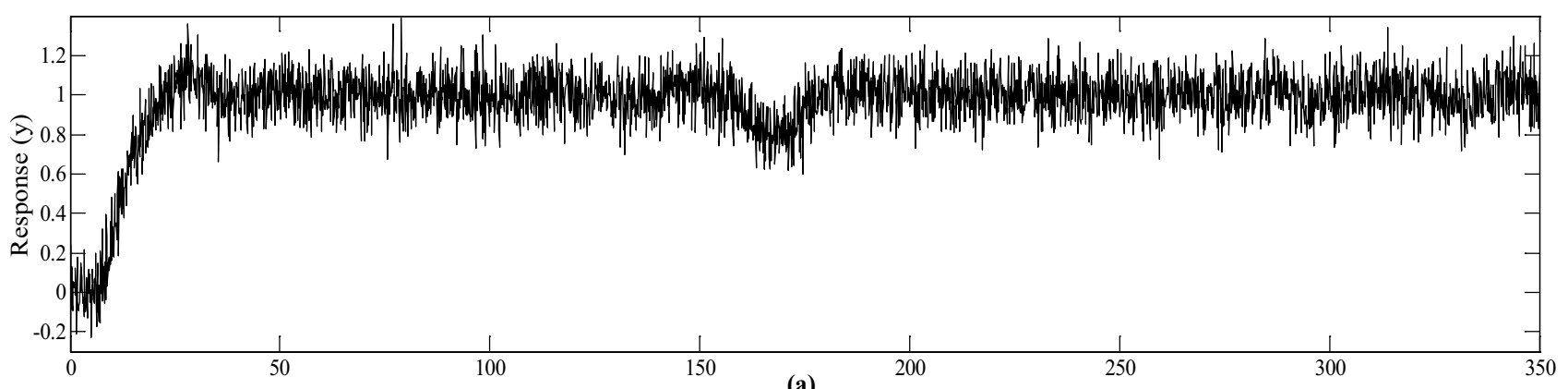

(a)

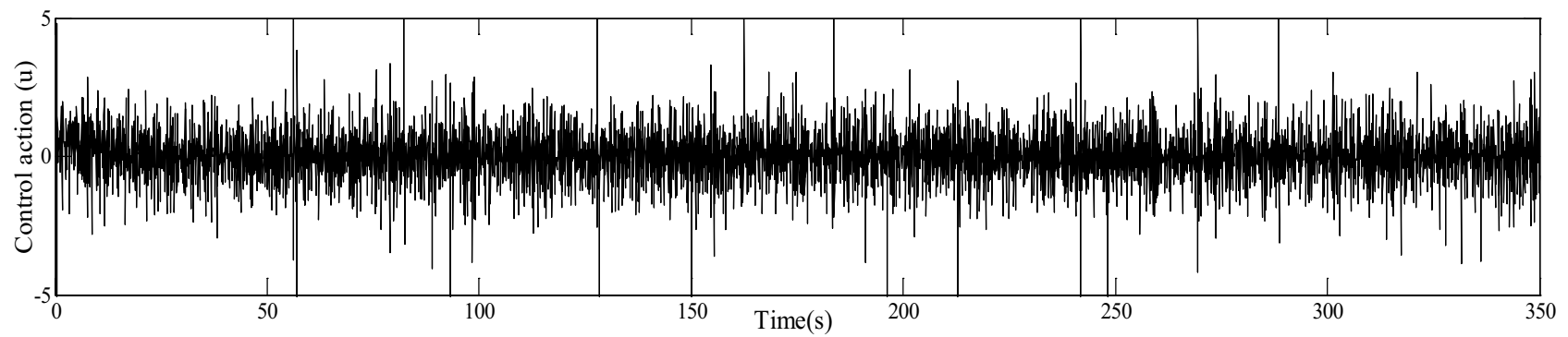

(b)

Fig. 8 Set point tracking and load rejection response along with effective control action for nominal Model II in presence of noise signal for the proposed controller

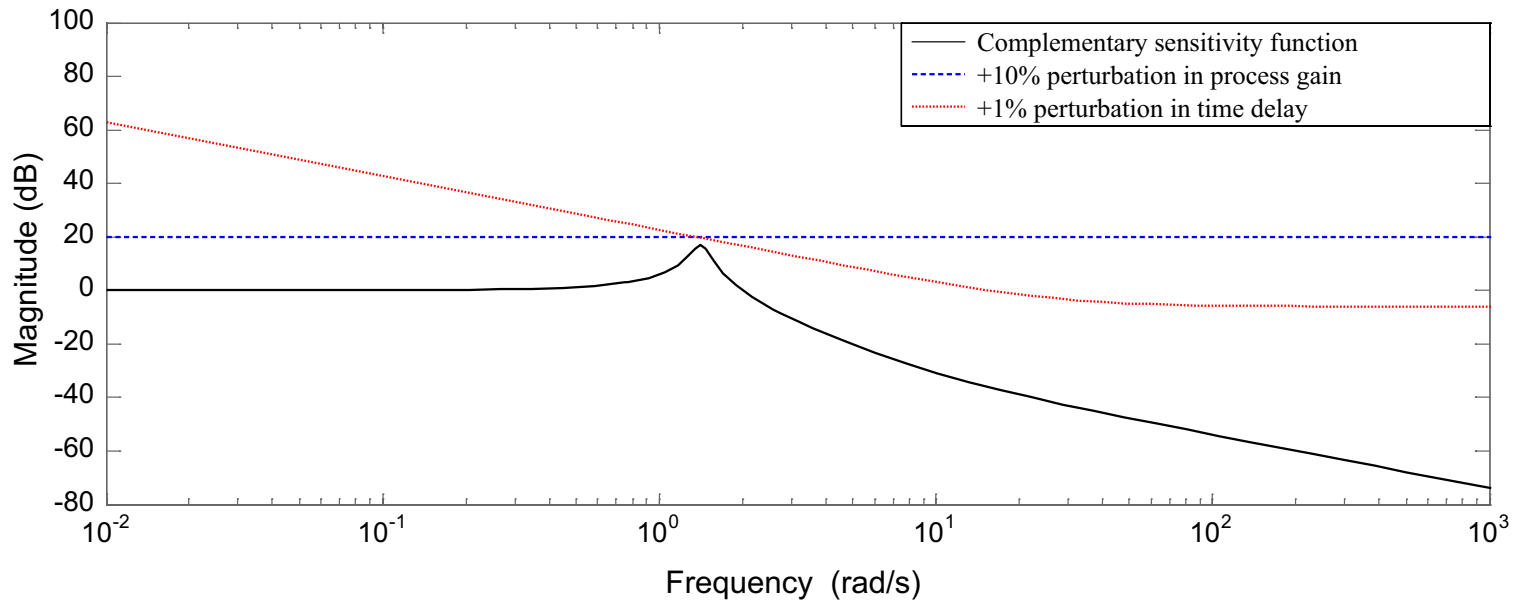

Fig. 9 Magnitude plot of complementary sensitivity function $\mathrm{C}(\mathrm{j} \omega)$ with $+10 \%$ perturbation in process gain $\Delta \mathrm{K}_{\mathrm{m}}=0.02$ and $+1 \%$ perturbation in time delay $\Delta \theta=0.074$ for Model II

b, respectively. Stability of the process model is identified by small gain theorem [18] by introducing perturbation in process gain $\left(\Delta \mathrm{K}_{\mathrm{m}}\right)$ and time delay $(\Delta \theta)$ as depicted in Table 2 . The maximum range of perturbation by which the stability can be achieved is shown in Fig. 9, where the complementary sensitivity function $C(j \omega)$ has the lesser amplitude than the perturbed value of process gain and time delay of the particular model. Here, stability is ensured with smaller perturbation in time delay as the concerned FOPTD model has relatively large dead time.
$\hat{\mathrm{G}}_{\mathrm{p} 2}(\mathrm{~s})=\frac{0.24}{\mathrm{~s}} \mathrm{e}^{-8.88 \mathrm{~s}}$

Close-loop responses and the corresponding control action for the perturbed model are shown in Fig. 7b, $d$ and the related performance indices are listed in Tables 3 and 4. Due to incorporation of set point weighting scheme $(\varepsilon=0.5)$, it is found that our proposed scheme is capable to restrict the overshoot during set point tracking and an overall performance enhancement is 


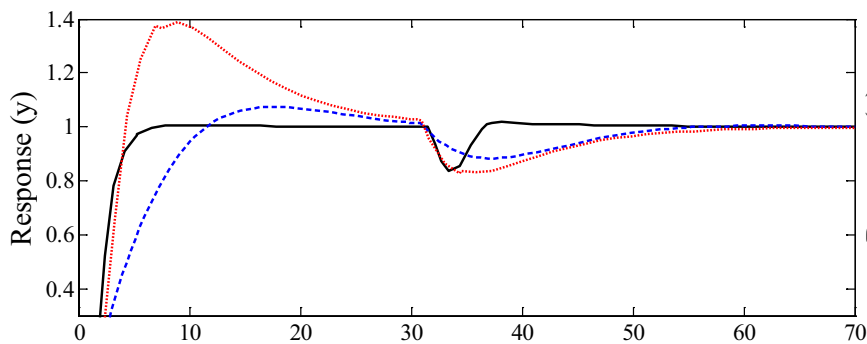

(a)

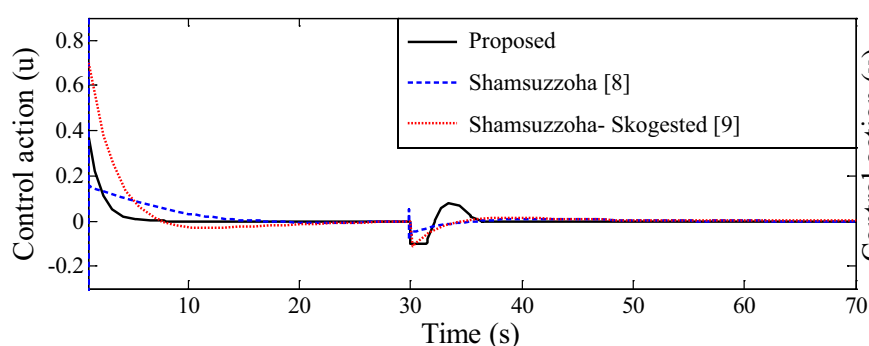

(c)

Nominal model III

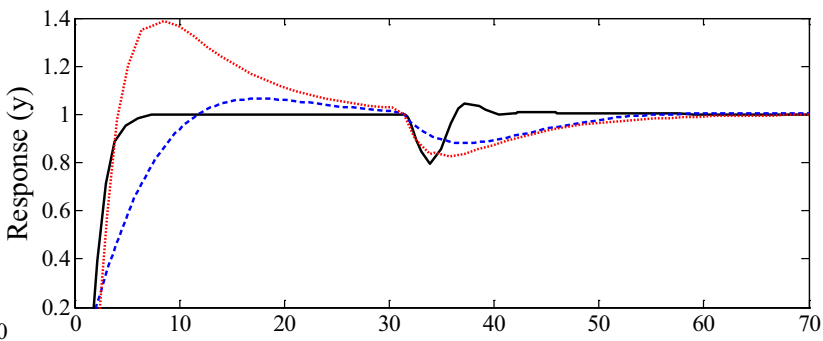

(b)

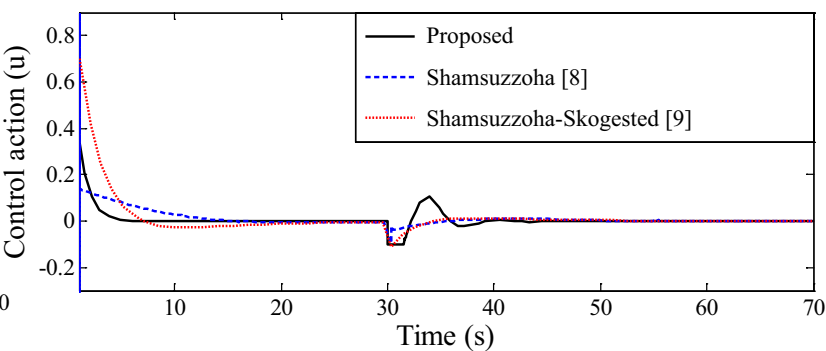

(d)

Perturbed model III

Fig. 10 Set point tracking and load rejection responses along with control actions for nominal and perturbed Model III

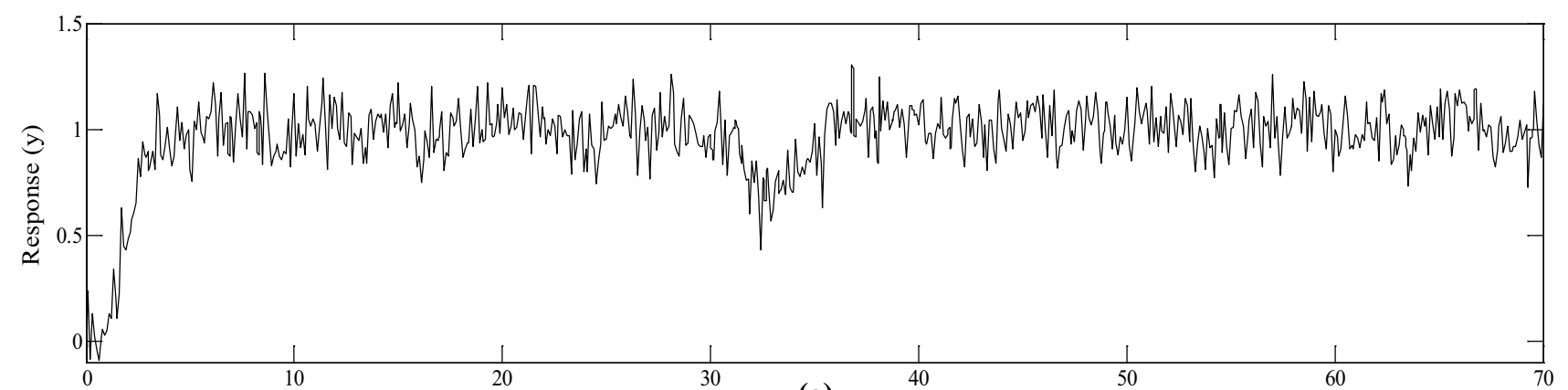

(a)

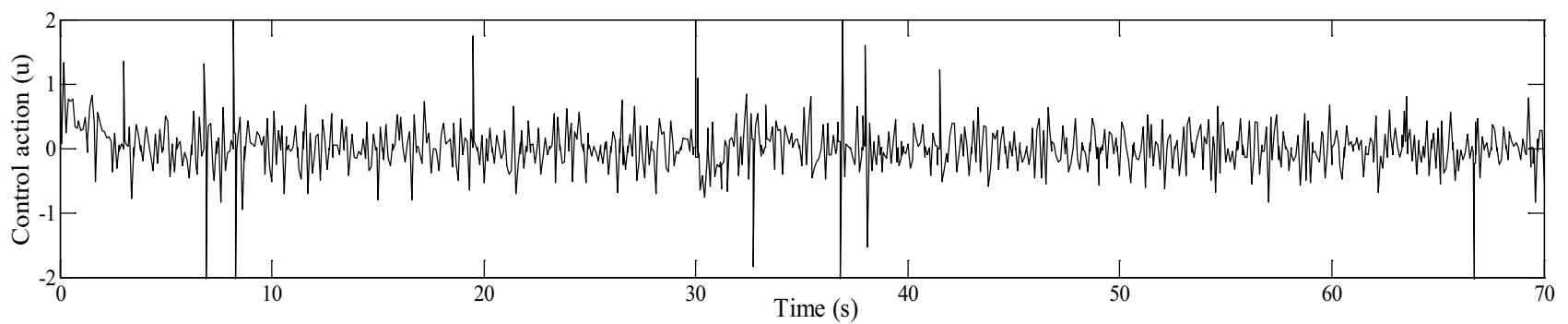

(b)

Fig. 11 Set point tracking and load rejection response along with effective control action for nominal Model III in presence of noise signal for the proposed controller

observed compared to modified Smith predictor techniques reported by Shamsuzzoha and Lee [21], and Wang et al. [22].

\subsection{Model III}

We consider another reputed integrating FOPTD model (i.e. Model III) reported by Shamsuzzoha [8], and 


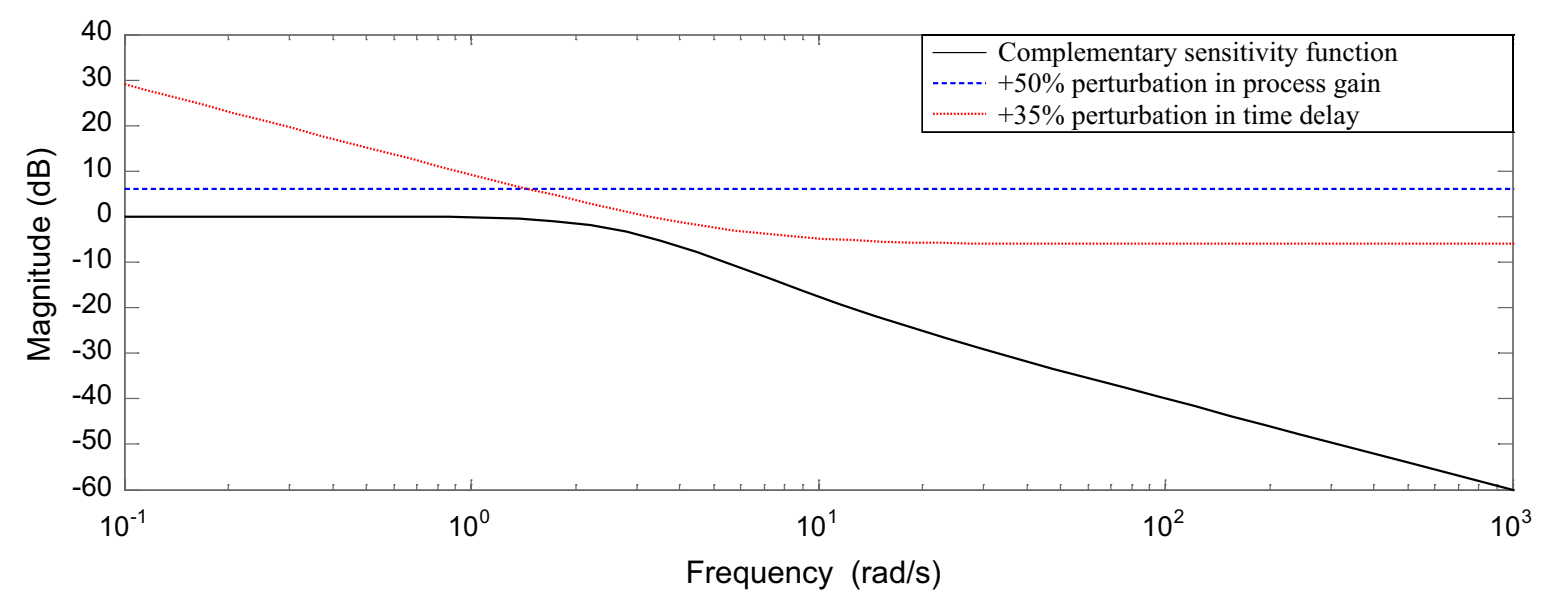

Fig. 12 Magnitude plot of complementary sensitivity function $\mathrm{C}(\mathrm{j} \omega)$ with $+50 \%$ perturbation in process gain $\Delta \mathrm{K}_{\mathrm{m}}=0.5$ and $+35 \%$ perturbation in time delay $\Delta \theta=0.35$ for Model III

Shamsuzzoha and Skogested [9] for performance evaluation of the proposed methodology. Model III is given by the following relation

$\mathrm{G}_{\mathrm{p} 3}(\mathrm{~s})=\frac{1}{\mathrm{~s}} \mathrm{e}^{-\mathrm{s}}$.

Responses and related variation in control action of the Model III during set point tracking and load change for the proposed methodology along with settings reported by Shamsuzzoha [8], and Shamsuzzoha and Skogested [9] are depicted in Fig. 10a, c. Performance evaluation is also made for the reported controllers by introducing $+10 \%$ perturbation in Model III as given by Eq. (31). Robustness of the proposed control technique is verified during close-loop responses in presence of noise signal (Fig. 3). Responses and control actions for nominal process model (Eq. 30) depicted in Fig. 11a, b. Moreover, stability is ensured by incorporating perturbation in process gain $\left(\Delta \mathrm{K}_{\mathrm{m}}\right)$ and time delay $(\Delta \theta)$ as depicted in Table 2. Condition for stability is achieved for our proposed scheme with the perturbed value of process gain $\left(\Delta \mathrm{K}_{\mathrm{m}}\right)$ and time delay $(\Delta \theta)$ as shown in Fig. 12.

$\hat{\mathrm{G}}_{\mathrm{p} 3}(\mathrm{~s})=\frac{1.1}{\mathrm{~s}} \mathrm{e}^{-1.1 \mathrm{~s}}$.

Responses of the perturbed model are shown in Fig. 10b, d. Performance indices for both the nominal (Eq. 30) and perturbed models (Eq. 31) during set point tracking and load recovery phases are listed in Tables 3 and 4. Due to incorporation of set point weighting $(\varepsilon=0.9)$ in the proposed methodology no process overshoot is obtained. In addition, load recovery response is also found to be considerably improved compared to the performance offered by Shamsuzzoha [8], Shamsuzzoha and Skogested [9],

\section{SN Applied Sciences}

\section{Conclusion}

In this paper, a simple modified Smith predictor technique is reported for integrating FOPTD models representing the behaviour of various chemical processes. Moreover, only two controllers with their simplified tuning rule is capable to offer improved performance during set point tracking and load rejection phases. The advantage of the proposed tuning technique is that hardly any overshoot can be detected during set point tracking along with relatively faster load rejection is observed for most of the cases. Set point weighting scheme is introduced with the feed-forward controller to ensure improved set point tracking without overshoot whereas the other controller takes the responsibility to eliminate undesired disturbances. The proposed tuning methodology is relatively simple and effective compared to the others' reported control techniques proposed in relation to the modified Smith predictor. Stability and robustness of the proposed scheme is verified by small gain theorem using complementary sensitivity function of the process model and for perturbed values of process gain and time delay. Moreover, designer has the option to ascertain more judicious choice of the tuning parameters for controllers towards further close-loop performance enhancement.

\section{Compliance with ethical standards}

Conflict of interest The authors declare that they have no conflict of interest. 


\section{References}

1. Dwyer AO (1996) The estimation and compensation of processes with time delays. Ph.D. Thesis, Dublin City University, Ireland

2. Normey-Richo JE, Camacho EF (2007) Control of dead-time processes. Springer, London

3. Smith OJM (1959) A controller to overcome dead time. ISA Trans 6(2):28-33

4. Watanabe K, Ito M (1981) A process-model control for linear systems with delay. IEEE Trans Autom Control 26(6):1261-1269

5. De Paor AM, Egan RP (1989) Extension and partial optimization of a modified Smith predictor and controller for unstable processes with time delay. Int J Control 50(4):1315-1326

6. Aström KJ, Hang CC, Lim BC (1994) A new Smith predictor for controlling a process with an integrator and long dead time. IEEE Trans Autom Control 39(2):343-345

7. Matušek MR, Micić AD (1996) A modified Smith predictor for controlling a process with an integrator and long dead-time. IEEE Trans Autom Control 41(8):1199-1203

8. Shamsuzzoha M (2013) Closed-loop PI/PID controller tuning for stable and integrating processes. Ind Eng Chem Res 52(36):12973-12992

9. Shamsuzzoha M, Skogested S (2010) The set point overshoot method: a simple and fast closed-loop approach for PID tuning. J Process Control 20(10):1220-1234

10. Liu T, Cai YZ, Gu DY, Zhang WD (2005) New modified Smith predictor scheme for integrating and unstable processes with time delay. IEE Proc Control Theory Appl 152(2):238-246

11. Majhi S, Atherton DP (2000) Obtaining controller parameters for a new Smith predictor using auto-tuning. Automatica 36(11):1651-1658

12. Kaya I, Atherton DP (1999) A new PI-PD Smith predictor for control of process with long dead time. In: Proceedings of the 14th IFAC world congress

13. Kaya I (2003) Obtaining controller parameters for a new PI-PD Smith predictor using auto tuning. J Process Control 13(5):465-472
14. Harriott P (2003) Chemical reactor design. Marcel Dekker, New York

15. Bissel C (1994) Control engineering. CRC Press, London

16. Routh EJ (1905) Dynamics of a system of rigid bodies. Part II. MacMillan, London

17. Boyce W, Diprima R (1992) Ordinary differential equations and boundary value problems, 5th edn. Wiley, New York

18. Rao AS, Chidambaram M (2008) Analytical design of modified Smith predictor in a two-degrees-of-freedom control scheme for second order unstable processes with time delay. ISA Trans 47(4):407-419

19. Rao AS, Rao VSR, Chidambaram M (2007) Set point weighted modified Smith predictor for integrating and double integrating processes with time delay. ISA Trans 46(1):59-71

20. Padhan DG, Majhi S (2011) Modified Smith predictor and controller for time delay processes. Electron Lett 47(17):959-961

21. Shamsuzzoha M, Lee M (2007) IMC-PID controller design for improved disturbance rejection of time-delayed processes. Ind Eng Chem Res 46(7):2077-2091

22. Wang Q, Lu C, Pan W (2016) IMC PID controller tuning for stable and unstable processes with time delay. Chem Eng Res Des 105:120-129

23. Uma S, Rao S (2016) Enhanced modified Smith predictor for second-order non-minimum phase unstable processes. Int J Syst Sci 47(4):966-981

24. Mehta U, Kaya I (2017) Smith predictor with sliding mode control for processes with large dead times. J Electr Eng 68(6):463-469

25. Mehta U, Rojas R (2017) Smith predictor based sliding mode control for a class of unstable processes. Trans Inst Meas Control 39(5):706-714

Publisher's Note Springer Nature remains neutral with regard to jurisdictional claims in published maps and institutional affiliations. 